\title{
Inflationary effects of oil prices and domestic gasoline prices: Markov-switching-VAR analysis
}

\author{
Selin Ozdemir ${ }^{1} \cdot$ Işil Akgul $^{1}$
}

Received: 9 April 2014/Published online: 7 April 2015

(c) The Author(s) 2015. This article is published with open access at Springerlink.com

\begin{abstract}
The purpose of this study is to contribute to the literature by studying the effects of sudden changes both on crude oil import price and domestic gasoline price on inflation for Turkey, an emerging country. Since an inflation targeting regime is being carried out by the Central Bank of Turkey, determination of such effects is becoming more important. Therefore empirical evidence in this paper will serve as guidance for those countries, which have an inflation targeting regime. Analyses have been done in the period of October 2005-December 2012 by Markovswitching vector autoregressive (MS-VAR) models which are successful in capturing the nonlinear properties of variables. Using MS-VAR analysis, it is found that there are 2 regimes in the analysis period. Furthermore, regime changes can be dated and the turning points of economic cycles can be determined. In addition, it is found that the effect of the changes in crude oil and domestic gasoline prices on consumer prices and core inflation is not the same under different regimes. Moreover, the sudden increase in gasoline price is more important for consumer price inflation than crude oil price shocks. Another finding is the presence of a pass-through effect from oil price and gasoline price to core inflation.
\end{abstract}

Keywords Crude oil price - Domestic gasoline price . Consumer price index · Core inflation $\cdot$ MS-VAR model

Selin Ozdemir

sozdemir@marmara.edu.tr

1 Department of Econometrics, Faculty of Economics, Marmara University, Istanbul, Turkey

Edited by Xiu-Qin Zhu

\section{Introduction}

Oil price has acquired increasing attention from both academicians and politicians after the dramatic rise in oil price in 1973 (Robert and Tatom 1977; Santini 1986; Mork 1989; Dotsey and Reid 1992; Davis et al. 1996; Hamilton 1996; Cunado and Perez de Gracia 2003; Cologni and Manera 2005; Kilian and Vigfusson 2009; Du et al. 2011; Reboredo 2011; Kilian and Murphy 2013). The reason is that understanding the inflationary effects caused by an increase of oil price can assist politicians and central banks to implement policies to get inflation under control.

Oil is one of the most important sources of energy, and the impacts of oil price fluctuations are risky in terms of the economies of countries. Fluctuation in oil price affects both the oil-importing and the oil-exporting countries. Especially in the non-oil-producing countries, oil price fluctuation can have a great impact on economic variables such as consumer prices and core inflation. Moreover, it is generally accepted that instant and huge changes in oil price can cause a rise in consumer prices and core inflation, which will result in economic recession in oil-importing countries.

The impacts of oil price increases on high inflation are basically reflected in three ways: the first impact appears because oil constitutes a proportion of household consumption. This proportion comprises processed products such as gasoline used for transportation and fuel used for heating, which fall into the household consumption basket within the consumer price index. The second impact is reflected in the form of consumer prices through producer prices. Firms and factories pass on the increase in energy prices to the prices of final products. In turn, this creates an impact on the consumer price index, which is an indirect effect. The third impact is that there could be an 
expectation of higher inflation and higher wages. In order to compensate for the decrease in real income, a negotiation process is conducted for wages. Production costs increase because of the rising of oil prices, which is called as a second round impact.

Based on the above factors, the Central Bank of the Republic of Turkey confirmed that oil price uncertainty is a risk factor with regard to inflation for Turkey, which carries out an inflation targeting regime (CBRT Monetary Policy Report 2012). Furthermore, it has been indicated that the emergence of oil supply problems could lead to an increase in energy prices; consequently, it could exacerbate the expectation of inflation, and eventually necessary steps would need to be taken to prevent it. Therefore, this paper discusses a topic that is on the agenda, and aims to determine whether shocks in oil and gasoline prices constitute a risk to consumer price inflation and core inflation.

Various researchers have investigated the relationship between oil price and inflation in Turkey. But only a few studies have investigated whether the relationship is nonlinear. Oil price and inflation series may exhibit nonlinear behavior due to factors such as policy changes, energy crises, etc. Thus, if oil price and inflation data exhibit structural regime shifts, then a model assuming constant parameters, mean, and variance is likely to yield misleading results. Therefore, modeling the relationship between oil price and inflation within a nonlinear framework is more suitable.

This paper investigates the effect of a nonlinear relationship between crude oil import price and domestic gasoline price on consumer price inflation and core inflation, and differs from the existing literature using Markovswitching vector autoregressive (MS-VAR) models. The paper proceeds as follows: Section 2 presents a review of previous studies on the empirical evidence of oil price changes and their effects on inflation. Section 3 deals with data used in the analysis, methodological issues, and the empirical analysis. Section 4 concludes with a summary and policy implications.

\section{Previous studies}

Several researchers have investigated the relationship between oil prices and inflation using different econometric approaches, countries, and sample periods. The relevant literature includes the following studies: Kahn and Hampton (1990), Huntington (1998), LeBlanc and Chinn (2004), Cunado and Perez de Gracia (2005), Ewing and Thompson (2007), Farzanegan and Markwardt (2009), De Gregorio et al. (2007), Tang et al. (2010), and Álvarez et al. (2011). These studies reveal that inflation is affected by oil price. Kahn and Hampton (1990) investigate whether increases in oil price affect the U.S. economy and find that in the short run, higher oil prices can increase inflation and lower real GNP. Huntington (1998) examines the linkages between oil price and inflation from a different perspective and finds that consumer prices appear to respond asymmetrically to energy price increase and decrease in the U.S. LeBlanc and Chinn (2004) show that oil price increases are likely to have only a modest effect on inflation in the U.S., Japan, and Europe. By taking a nonlinear relationship into account, Cunado and Perez de Gracia (2005) report that oil prices have permanent effects on inflation and asymmetric effects on the GNP in European countries. Medina and Soto (2007) use a dynamic stochastic general equilibrium and show that a $13 \%$ increase in the real price of oil leads to an increase in inflation of about $0.4 \%$ in the Chilean economy. Ewing and Thompson (2007) investigate the cyclical co-movements of crude oil price with consumer prices using Hodrick-Prescott methodology. Their findings support that the price of oil is the leading factor in consumer prices in the U.S. Farzanegan and Markwardt (2009) analyze the dynamic relationship between oil price shocks and major macroeconomic variables in Iran by applying a VAR approach. They identify that negative oil price shocks significantly increase inflation. De Gregorio et al. (2007) estimate a Phillips curve equation with lags of inflation, the output gap, and the percentage change in the price of oil for 24 industrial economies and 12 emerging economies. Their study shows the effects of oil shocks on the general level of prices. Van den Noord and André (2007) conclude that the spillover effects of energy prices into core inflation are small in comparison with the effects of the 1970s. Tang et al. (2010) provide statistical support for the adverse economic impacts of oil price shocks for developed economies. Their results show that an oil price increase negatively affects output and investment, but positively affects inflation rate and interest rate. Álvarez et al. (2011) examine the impact of oil price changes on Spanish and euro area consumer price inflation using linear and nonlinear models. They find that crude oil price fluctuations are major drivers of inflation variability.

However, at least some studies in the literature show evidence contradicting the results showing that oil price and inflation are linked. Hooker (2002) examines the effects of oil price shocks on inflation in Phillips curve models that allow structural breaks, and he reports that oil price shocks have caused an increase in inflation in the U.S. before 1981. However, in recent periods this impact was negligible. Also, Olomola and Adejumo (2006) evaluate the effects of oil price changes on output, inflation, real exchange rate, and money supply in Nigeria using VAR models. They find that oil price shocks do not have any substantial effect on output and inflation. 
When limited numbers of articles that elaborate the impact of oil price changes on inflation in Turkey are examined, it is seen that nonlinearity has been neglected. Kibritcioglu and Kibritcioglu (1999) analyze the effect of oil price shocks on the general price level. They suggest that a $20 \%$ increase in the price of crude oil has an insignificant effect on the general price level. Berument and Tasci (2002) use an input-output table and conclude that general price level increases for a given increase in the price of oil depend on the behavior of the wages, profits, interest, and rents. Aktas et al. (2010) carry out a VAR model and observe that a positive relationship between oil price and inflation exists. They assert that a response of macroeconomic variables against oil price shocks becomes stationary only after 1 year. Aydin and Acar (2011) analyze the economic effects of oil price shocks by developing a dynamic multi-sectoral general equilibrium model. Their results show that the price of oil has significant effects on consumer price inflation. Nazlioglu and Soytas (2011) examine the interdependence between world oil prices and individual agricultural commodity prices using the TodaYamamoto causality approach and generalized impulseresponse analysis. Their results reveal the neutrality of agricultural commodity markets to the effects of oil price changes. Oksuzler and Ipek (2011) examine whether negative oil supply shocks can increase inflation. According to the results of Granger causality analysis, they find that there is no causality between oil price and inflation, but impulse-response functions showed that a positive oil price shock increases inflation. The empirical evidence obtained from a bound testing approach in the study of Peker and Mercan (2011) shows that the inflationary effect of oil products price increases is positive and statistically significant in the long term. Celik and Akgul (2011) investigate whether there is a linkage between the consumer price index and the fuel oil price index using the vector error correction model. Their results reveal that a $1 \%$ increase in fuel oil prices can cause the consumer price index to rise by $1.26 \%$. Yaylali and Lebe (2012) specify the importance of crude oil prices in the general level of prices by employing Vector Autoregressive methodology. By identifying the source of change in inflation, their analysis results show that import crude oil prices are one of the important sources of inflation in Turkey. With a different approach, Catik and Onder (2011) investigate the oil price passthrough inflation for Turkey by considering nonlinearity. They find evidence for asymmetric oil pass-through in the high inflation regime by estimating Markov-switching (MS) models. In contrast to these studies, in this article, the effects of the relationship between crude oil import price and domestic gasoline prices on consumer price inflation and core inflation are examined separately using nonlinear models.

\section{Data and econometric methodology}

\subsection{Data}

The aim of this study is to empirically investigate the effects of sudden changes in the crude oil import price on inflation in Turkey. We use the first difference of logarithmic crude oil price (Brent-\$/barrel) (OIL) and the first difference of logarithmic unleaded gasoline price (\$/ barrel) (DGAS) in the analyses. Also, inflation (INF) and core inflation (CINF) are calculated using the first difference of logarithmic consumer price index and logarithmic special comprehensive consumer price index, which excludes energy. Crude oil prices are taken from the Federal Reserve Bank of St. Louis Data Delivery page. ${ }^{1}$ Historical domestic gasoline prices (TL/liter), which are available on the OPET company web page, ${ }^{2}$ are added to the analysis with the values ( $\$ /$ barrel) obtained through the transformation. Consumer price indexes are taken from the Turkish Statistical Institute corporate web page. ${ }^{3}$ We employ monthly data from October 2005 to December 2012. The choice of October 2005 as the starting period is based on the following: Between 2002 and 2006, implied inflation targeting was applied by the Central Bank of the Republic of Turkey; at the beginning of 2006 they adopted explicit inflation targeting, so analysis can be made starting from 2006. But to prevent any loss of data, the analysis period was initiated at October 2005.

\subsection{Econometric methodology}

Ever since the study by Hamilton (1989), Markov regimeswitching models have been utilized by researchers for modeling many macroeconomic time series, which exhibit asymmetries and nonlinear behavior (Hansen 1992; Goodwin 1993; Gray 1996; Cologni and Manera 2009). Therefore, the use of the MS approach has become popular for determining asymmetries. Goldfeld and Quandt (1973) introduced the MS model, in which the latent state variable controls the regime shifts. Hamilton (1989) and Krolzig (1998) made important contributions by developing the MS-VAR model, which is able to characterize macroeconomic fluctuations in the presence of structural breaks or shifts. These approaches allow researchers to overcome the shortcomings of linear models in dealing with the asymmetry between expansions and contractions.

In these models, parameters of the VAR model depend on the regime variable $\left(S_{t}\right)$, which makes the process regime dependent. The general idea behind this class of

\footnotetext{
${ }^{1}$ http://research.stlouisfed.org/fred2/.

${ }^{2}$ http://www.opet.com.tr/tr/PompaFiyatlariArsiv.aspx ?cat=4\&id=34.

${ }^{3}$ http://www.tuik.gov.tr/UstMenu.do?metod=temelist.
} 
regime-switching models is that the parameters of a $K$ dimensional time series vector $y_{t}=\left(y_{1 t}, \ldots, y_{K t}\right)^{\prime}, t=$ $1, \ldots, T$,

$y_{t}=v+A_{1} y_{t-1}+\cdots+A_{p} y_{t-p}+u_{t}$,

where $u_{t} \sim \operatorname{IID}\left(0, \sum\right)$ and $y_{0}, \ldots, y_{1-p}$ are fixed. The general idea behind the MS-VAR models is that the parameters of the underlying data-generating process of the observed time series vector $y_{t}$ depend on the unobservable regime variable $s_{t}$, which represents the probability of being in a different state. The assumption of the MS model is that the unobservable realization of the regime $s_{t} \in\{1, \ldots, M\}$ is governed by a discrete time, discrete state Markov stochastic process, which is defined by the transition probabilities,

$p_{i j}=\operatorname{Pr}\left(s_{t+1}=j \mid s_{t}=i\right), \sum_{j=1}^{M} p_{i j}=1 \forall_{i}, \quad j \in\{1, \ldots, M\}$.

It is assumed that $s_{t}$ follows an irreducible ergodic $M$ state Markov process with the transition matrix.

$P=\left[\begin{array}{cccc}p_{11} & p_{12} & \cdots & p_{1 M} \\ p_{21} & p_{22} & \cdots & p_{1 M} \\ \vdots & \vdots & \ddots & \vdots \\ p_{11} & p_{12} & \cdots & p_{1 M}\end{array}\right]$,

where $p_{i M}=1-p_{i 1}-\cdots-p_{i, M-1}$ for $i=1, \ldots, M$. We can write the MS-VAR model of order $p$;

$y_{t}=v\left(s_{t}\right) A_{1}\left(s_{t}\right) y_{t-1}+\cdots+A_{p}\left(s_{t}\right) y_{t-p}+u_{t}$,

where $u_{t} \sim \operatorname{NID}\left(0, \sum\left(s_{t}\right)\right)$. The parameter shift functions and $v\left(s_{t}\right), A_{1}\left(s_{t}\right), \ldots, A_{p}\left(s_{t}\right)$, and $\sum\left(s_{t}\right)$ describe the dependence of the parameters on the realized regime $s_{t}$,

$v\left(s_{t}\right)=\left\{\begin{array}{cc}v_{1} & \text { if } s_{t}=1, \\ \vdots & \\ v_{M} & \text { if } s_{t}=M\end{array}\right.$

The MS-VAR model allows for a variety of specifications. Krolzig (1997) made a representation with the general MS models with regime-dependent parameters in order to establish a common notation for each model, such as MSM-VAR, MSH-VAR, and MSIH-VAR.

Recently, there have been some developments in impulse-response relations in nonlinear models. Koop et al. (1996) offer a general analysis of impulse responses in nonlinear models and introduce the concept of generalized impulse response, which can measure the responses of the system to shocks to the variables in $h$ period as,

$\operatorname{IR}_{\nabla u}(h)=E\left[y_{t+h} \mid \xi_{t}, u_{t}+\nabla_{u} ; Y_{t-1}\right]-E\left[y_{t+h} \mid \xi_{t}, u_{t} ; Y_{t-1}\right]$,

where $\nabla_{u}$ is the shock at time $t$ and the responses to shocks to the variables as in the case of the linear VAR process,
$\operatorname{IR}_{u k}(h)=\frac{\partial E\left[y_{t+h} \mid \xi_{t}, u_{t} ; Y_{t-1}\right]}{\partial u_{k t}}$.

And the responses to shifts in regime are defined in the spirit of the generalized impulse-response concept:

$\operatorname{IR}_{\nabla u}(h)=E\left[y_{t+h} \mid \xi_{t}+\nabla \xi, u ; Y_{t-1}\right]-E\left[y_{t+h} \mid \xi_{t}, u_{t} ; Y_{t-1}\right]$,

where $\nabla \xi$ is the shift in regime at time $t$.

Estimating MS-VAR models that are based on Hamilton's (1989) algorithm consists of two steps. In the first step, population parameters, including the joint probability density of unobserved states, are estimated, and in the second step probabilistic inferences about the unobserved states are made using a nonlinear filter and smoother. Filtered probabilities are inferences about $s_{t}$ 's conditional on information up to time $t$, and smoothed probabilities are inferences about $s_{t}$ using all information available in the sample. However, this method becomes more disadvantageous as the number of parameters to be estimated increases. Accordingly, the expectation maximization algorithm, originally described by Dempster et al. (1977) is used. This technique starts with the initial estimates of the hidden data and iteratively produces a new joint distribution that increases the probability of observed data.

\subsection{Empirical analysis}

The analysis was initiated by calculating the certain statistics of the series used in the study, and the results are given in Table 1.

According to the Jarque-Bera test statistics in Table 1, INF and CINF series are normally distributed but OIL and DGAS series are not. Also the series are found to be stationary at the $5 \%$ level of significance using Dickey and Fuller (1979) $\tau$-test statistics. However, it is known that DF-type unit root tests are not strong in case of a regime change in the series. Therefore, the MS-ADF test, which is a unit root test appropriate for MS models, is also applied (Hall et al. 1999) and it is confirmed that the series are stationary. In order to reveal the nonlinear structure in the

Table 1 Descriptive statistics of series

\begin{tabular}{lrrrr}
\hline & \multicolumn{1}{c}{ INF } & \multicolumn{1}{c}{ CINF } & \multicolumn{1}{c}{ OIL } & DGAS \\
\hline Mean & 0.67 & 0.65 & 0.34 & 0.26 \\
SD & 0.84 & 0.99 & 9.35 & 4.94 \\
Skewness & 0.32 & 0.10 & -1.16 & -1.33 \\
Kurtosis & 3.20 & 2.63 & 5.62 & 7.63 \\
Jarque-Bera & 1.71 & 0.62 & 44.80 & 103.51 \\
ADF & -7.37 & -7.49 & -6.21 & -6.55 \\
MS-ADF & -6.14 & -5.36 & -5.19 & -5.59 \\
\hline
\end{tabular}


Table 2 Results of linearity test

\begin{tabular}{lllllllllll}
\hline & $d=1$ & $d=2$ & $d=3$ & $d=4$ & $d=5$ & $d=6$ & $d=7$ & $d=8$ & $d=9$ & $d=10$ \\
\hline INF & 0.50 & 2.77 & 0.91 & 1.14 & 0.85 & 1.33 & 0.69 & 0.47 & 0.57 & 0.51 \\
$p$ value & 0.44 & $0.02 *$ & 0.15 & 0.04 & 0.15 & 0.09 & 0.25 & 0.42 & 0.34 & 0.43 \\
CINF & 0.32 & 0.51 & 1.13 & 3.29 & 0.84 & 0.74 & 0.98 & 0.77 & 0.63 & 0.21 \\
$p$ value & 0.67 & 0.53 & 0.11 & $0.01 *$ & 0.43 & 0.44 & 0.22 & 0.44 & 0.59 & 0.75 \\
OIL & 0.99 & 3.08 & 1.24 & 1.14 & 0.75 & 0.77 & 0.89 & 0.60 & 0.44 & 0.32 \\
$p$ value & 0.64 & $0.02 *$ & 0.09 & 0.11 & 0.32 & 0.33 & 0.27 & 0.44 & 0.86 & 0.85 \\
DGAS & 0.62 & 1.14 & 3.01 & 1.21 & 1.99 & 0.87 & 0.92 & 0.79 & 0.51 & 0.52 \\
$p$ value & 0.73 & 0.25 & $0.01^{*}$ & 0.19 & 0.09 & 0.31 & 0.47 & 0.50 & 0.63 & 0.66 \\
\hline
\end{tabular}

Significance at $5 \%$ is denoted with asterisks

Table 3 LR test results

\begin{tabular}{lllll}
\hline & INF-OIL & INF-DGAS & CINF-OIL & CINF-DGAS \\
\hline $\begin{array}{l}\text { Ho: linear VAR } \\
\text { Ha: two-regime MS-VAR }\end{array}$ & $61.04 *$ & $59.14 *$ & $64.18^{*}$ & $62.19^{*}$ \\
Ho: two-regime MS-VAR & 11.02 & 9.07 & 12.41 & 10.77 \\
Ha: three-regime MS-VAR & & & & \\
\hline
\end{tabular}

Significance at $5 \%$ is denoted with asterisks

series, the approach suggested by Tsay (1989) is used, and the linearity test results for different delay lengths are presented in Table 2.

The probability values reported in Table 2 calculated for 10 delay show that linearity is rejected more strongly in the second delay for INF and OIL, in the third delay for DGAS, and in the fourth delay for CINF. Afterward, an LR test is made in order to determine the number of regimes of the models, which is the first stage of model selection. Subsequently, the linear VAR model is tested against the 2-regime MS-VAR model. And later the 2-regime MSVAR model is tested against the 3-regime MS-VAR model.

According to the results shown in Table 3, it is determined that the 2-regime MS-VAR models are appropriate for the analyses. Using the Schwarz Information Criterion, the delay lengths are selected and it is decided that for INF-OIL, $\operatorname{MSI}(2)-\operatorname{VAR}(8)$; for INF-DGAS, MSI(2)-VARX(2); for CINF-OIL, MSIAH(2)-VAR(5) and for CINF-DGAS, MSIA(2)-VARX(8) models are appropriate. The MSI(2)VAR(8) model is estimated for INF-OIL and given in Table 4.

Regime 1 represents low inflation; regime 2 represents high inflation periods in the model. As seen in Table 4, the effect of oil price change on inflation is significant and positive in time $t-2$ and $t-3$. Transition probabilities and regime durations are given in Table 5 .

According to the regime probabilities shown in Table 5, it is seen that the probability of staying in the low inflation
Table 4 MSI(2)-VAR(8) model for INF-OIL

\begin{tabular}{|c|c|c|}
\hline & INF & OIL \\
\hline Constant (Reg. 1) & $0.82 *(4.16)$ & $1.27(0.65)$ \\
\hline Constant (Reg. 2) & $1.62 *(7.07)$ & $11.57 *(5.05)$ \\
\hline $\mathrm{INF}_{t-1}$ & $-0.04(-0.46)$ & $-1.94 *(-1.99)$ \\
\hline $\mathrm{INF}_{t-2}$ & $-0.09(-0.97)$ & $-0.50(-0.55)$ \\
\hline $\mathrm{INF}_{t-3}$ & $-0.17 *(-2.01)$ & $-0.24(-1.14)$ \\
\hline $\mathrm{INF}_{t-4}$ & $-0.31 *(-3.44)$ & $-1.60 *(-1.99)$ \\
\hline $\mathrm{INF}_{t-5}$ & $-0.08(-0.84)$ & $-0.16(-0.17)$ \\
\hline $\mathrm{INF}_{t-6}$ & $0.16(1.68)$ & $-1.04(-1.05)$ \\
\hline $\mathrm{INF}_{t-7}$ & $-0.18 *(-2.01)$ & $-2.09 *(-2.19)$ \\
\hline $\mathrm{INF}_{t-8}$ & $-0.17(-1.81)$ & $-1.26(-1.31)$ \\
\hline $\mathrm{OIL}_{t-1}$ & $0.01(0.21)$ & $0.28 *(3.23)$ \\
\hline $\mathrm{OIL}_{t-2}$ & $0.02 *(2.29)$ & $0.21 *(2.32)$ \\
\hline $\mathrm{OIL}_{t-3}$ & $0.01 *(2.13)$ & $-0.04(-0.49)$ \\
\hline $\mathrm{OIL}_{t-4}$ & $-0.03(-0.38)$ & $0.08(0.95)$ \\
\hline $\mathrm{OIL}_{t-5}$ & $0.03(0.02)$ & $-0.19 *(-2.16)$ \\
\hline $\mathrm{OIL}_{t-6}$ & $0.00(1.08)$ & $-0.27 *(-3.11)$ \\
\hline $\mathrm{OIL}_{t-7}$ & $0.01(0.94)$ & $0.15(1.68)$ \\
\hline $\mathrm{OIL}_{t-8}$ & $0.01(1.91)$ & $-0.01(-0.19)$ \\
\hline
\end{tabular}

$t$ Statistics are given in parentheses (). Probabilities are given in parentheses []. Significance at $5 \%$ is denoted with asterisks

Log-likelihood: 154.12, AIC criterion: 9.79, LR linearity test: 16.50 $[0.03], \chi^{(2)}=[0.003], \chi^{(4)}=[0.002]$, Davies $=[0.004]$, Vector normality test: $\chi^{(4)}=4.57[0.18]$, Vector hetero test: $\chi^{(24)}=14.44$ [0.93], Vector portmanteau(5) $\chi^{(12)}=13.42$ [0.33] 
Table 5 Transition probabilities and regime durations for $\operatorname{MSI}(2)$ $\operatorname{VAR}(8)$

\begin{tabular}{lllll}
\hline Transition probabilities & Regime 1 & Regime 2 & Nobs & Durations \\
\hline Regime 1 & 0.68 & 0.32 & 39.9 & 3.08 \\
Regime 2 & 0.33 & 0.67 & 39.1 & 3.00 \\
\hline
\end{tabular}

Table 6 MSI(2)-VARX(2) model for INF-DGAS

\begin{tabular}{lcc}
\hline & INF & DGAS \\
\hline Constant (Reg. 1) & $-0.01(-0.11)$ & $-2.43^{*}(-3.34)$ \\
Constant (Reg. 2) & $1.09 *(7.56)$ & $3.01^{*}(4.22)$ \\
$\mathrm{INF}_{t-1}$ & $0.19 *(2.26)$ & $-1.07 *(-2.33)$ \\
$\mathrm{INF}_{t-2}$ & $0.07(0.88)$ & $0.18(0.41)$ \\
DGAS $_{t-1}$ & $0.07 *(3.84)$ & $0.11(1.29)$ \\
DGAS $_{t-2}$ & $0.03 *(2.65)$ & $0.11(1.40)$ \\
D1 & $2.59 *(4.27)$ & $-3.34^{*}(-6.06)$ \\
D2 & $1.76 *(2.32)$ & $-2.28^{*}(-2.35)$ \\
\hline
\end{tabular}

$t$ Statistics are given in parentheses (). Probabilities are given in parentheses []. Significance at $5 \%$ is denoted with asterisks

Log-likelihood: 134.88 , AIC criterion: 8.22 , LR linearity test: 12.52 $[0.04], \chi^{(2)}=[0.021], \chi^{(4)}=[0.012]$, Davies $=[0.031]$, Vector normality test: $\chi^{(4)}=3.73[0.23]$, Vector hetero test: $\chi^{(24)}=12.45$ [0.54], Vector portmanteau(5): $\chi^{(12)}=14.88[0.47]$

Table 7 Transition probabilities, regime durations for $\operatorname{MSI}(2)$ $\operatorname{VARX}(2)$

\begin{tabular}{lllll}
\hline Transition probabilities & Regime 1 & Regime 2 & Nobs & Durations \\
\hline Regime1 & 0.40 & 0.60 & 33.7 & 2.48 \\
Regime2 & 0.36 & 0.64 & 51.3 & 3.78 \\
\hline
\end{tabular}

is 0.68 and staying in the high inflation regime is 0.67 . Also, the first regime tends to last 3.08 months on average, while the second regime is less persistent with 3.00 months. The average period of 3 months reveals that the number of stages is high and the transitions are rapid. Also, it is seen that the low inflation and high inflation probabilities and transition probability from one regime to another are almost the same. Observation numbers of regime 1 and regime 2 and duration of remaining at one regime are approximately the same, as well. These results show that the stages of both regimes would be the same. The results obtained for INF-DGAS are reported in Table 6.

It is seen in Table 6 , the effect of gasoline price change on inflation is significant and positive in time $t-1$ and $t-2$. Transition probabilities and regime durations for MSI(2)-VARX(2) are given in Table 7.

According to the regime probabilities, it is seen that the probability of staying in the low inflation is 0.40 and staying in the high inflation regime is 0.64 . Also durations show that the first regime tends to last 2.48 months on average, while the second regime is more persistent, lasting 3.78 months. Transition probabilities show that there is a high probability of transition from low inflation to high inflation. This finding reveals that a sudden increase in domestic gasoline oil prices has the effect of a crisis, and this should be taken into consideration in adjusting gasoline prices to achieve the inflation target. The model selected for CINF-OIL is a MSIAH(2)VAR(5) model and the results are given in Table 8 .

The coefficient in Table 8 reveals that the effects of oil price change on core inflation is significant and positive in time $t-1$ but negative in $t-3$. Transition probabilities and regime durations are given in Table 9.

Table 8 MSIAH(2)-VAR (5) model for CINF-OIL

\begin{tabular}{|c|c|c|c|c|}
\hline & \multicolumn{2}{|l|}{ Regime 1} & \multicolumn{2}{|l|}{ Regime 2} \\
\hline & CINF & OIL & CINF & OIL \\
\hline Constant & $1.13 *(3.83)$ & $-1.68(-2.40)$ & $1.18 *(3.31)$ & $2.16 *(5.94)$ \\
\hline $\mathrm{CINF}_{t-1}$ & $-0.11(-0.92)$ & $0.90(0.59)$ & $0.35(1.40)$ & $1.10(2.53)^{*}$ \\
\hline $\mathrm{CINF}_{t-2}$ & $-0.35(-2.65)^{*}$ & $2.54(1.98)^{*}$ & $-0.40(-2.24)^{*}$ & $-1.86(-3.24)^{*}$ \\
\hline $\mathrm{CINF}_{t-3}$ & $-0.62(-4.07)^{*}$ & $4.08(2.07)^{*}$ & $-0.08(1.24)$ & $0.88(-0.79)$ \\
\hline $\mathrm{CINF}_{t-4}$ & $-0.52(-3.57)^{*}$ & $-1.26(-0.70)$ & $-0.06(-2.90)^{*}$ & $-2.05(-0.61)$ \\
\hline $\mathrm{CINF}_{t-5}$ & $0.23(1.66)$ & $2.25(1.22)$ & $-0.33(3.40)^{*}$ & $2.49(-2.79) *$ \\
\hline $\mathrm{OIL}_{t-1}$ & $0.02(2.96)^{*}$ & $0.40(2.18)^{*}$ & $0.01(-0.53)$ & $-0.04(0.86)$ \\
\hline $\mathrm{OIL}_{t-2}$ & $0.01(0.09)$ & $0.31(1.48)$ & $-0.02(-2.70)^{*}$ & $-0.22(-0.71)$ \\
\hline $\mathrm{OIL}_{t-3}$ & $-0.03(-2.71)^{*}$ & $0.25(1.20)$ & $0.02(1.44)$ & $0.12(1.53)$ \\
\hline $\mathrm{OIL}_{t-4}$ & $-0.02(-1.34)$ & $-0.13(-0.64)$ & $0.03(1.97)^{*}$ & $0.15(2.54)^{*}$ \\
\hline $\mathrm{OIL}_{t-5}$ & $0.03(2.25)^{*}$ & $-0.21(-1.20)$ & $-0.02(-1.91)^{*}$ & $-0.13(-1.41)$ \\
\hline
\end{tabular}

$t$ Statistics are given in parentheses (). Probabilities are given in parentheses []. Significance at $5 \%$ is denoted with asterisks Log-likelihood: 121.93, AIC criterion: 8.14, LR linearity test: 15.33 [0.04], $\chi^{(2)}=[0.024], \chi^{(4)}=[0.019]$, Davies $=[0.023]$, Vector normality test: $\chi^{(4)}=3.73[0.25]$; Vector hetero test: $\chi^{(24)}=10.45[0.47]$, Vector portmanteau(5): $\chi^{(12)}=13.42[0.43]$ 
Table 9 Transition probabilities, regime durations for MSIAH(2)-VAR (5)

\begin{tabular}{lllll}
\hline Transition probabilities & Regime 1 & Regime 2 & Nobs & Durations \\
\hline Regime 1 & 0.47 & 0.53 & 34.9 & 2.11 \\
Regime 2 & 0.36 & 0.64 & 56.1 & 2.80 \\
\hline
\end{tabular}

Table 10 MSIAH(2)-VARX (8) model for CINF-DGAS

\begin{tabular}{|c|c|c|c|c|}
\hline & \multicolumn{2}{|l|}{ Regime 1} & \multicolumn{2}{|l|}{ Regime 2} \\
\hline & CINF & DGAS & CINF & DGAS \\
\hline Constant & 0.49 (2.71)* & $2.31(2.74)^{*}$ & $0.90(4.76)^{*}$ & $0.76(0.86)$ \\
\hline $\mathrm{CINF}_{t-1}$ & $0.22(2.11)^{*}$ & $0.42(0.89)$ & $0.26(2.97)^{*}$ & $0.16(0.39)$ \\
\hline $\mathrm{CINF}_{t-2}$ & $0.25(2.23)^{*}$ & $2.50(4.75)^{*}$ & $-0.20(-2.64)^{*}$ & $0.08(0.22)$ \\
\hline $\mathrm{CINF}_{t-3}$ & $-0.39(-2.24)^{*}$ & $-0.89(-4.41)^{*}$ & $-0.14(-1.47)$ & $0.45(1.04)$ \\
\hline $\mathrm{CINF}_{t-4}$ & $-0.28(-3.02)^{*}$ & $1.42(3.31)^{*}$ & $0.14(1.34)$ & $-1.26(-2.68)^{*}$ \\
\hline $\mathrm{CINF}_{t-5}$ & $0.27(2.14)^{*}$ & $-3.34(-5.29)^{*}$ & $-0.23(-2.62)^{*}$ & $1.45(3.54)^{*}$ \\
\hline $\mathrm{CINF}_{t-6}$ & $0.66(5.18)^{*}$ & $0.67(1.06)$ & $0.17(2.14)^{*}$ & $0.09(0.22)$ \\
\hline $\mathrm{CINF}_{t-7}$ & $-0.37(-2.48)^{*}$ & $-3.28(-5.17)^{*}$ & $0.14(1.83)$ & $0.66(1.84)$ \\
\hline $\mathrm{CINF}_{t-8}$ & $-0.49(-4.08)$ & $-2.37(-4.37)^{*}$ & $0.03(0.35)$ & $0.50(0.97)$ \\
\hline DGAS $_{t-1}$ & $-0.01(-0.01)$ & $0.49(6.23)$ & $0.02(0.97)$ & $0.16(1.31)$ \\
\hline DGAS $_{t-2}$ & $-0.02(-1.26)$ & $-0.36(-3.72)^{*}$ & $0.01(0.23)$ & $-0.13(-1.46)$ \\
\hline DGAS $_{t-3}$ & $-0.05(-2.45)^{*}$ & $0.89(8.04)^{*}$ & $0.08(0.58)$ & 0.07 (1.06) \\
\hline DGAS $_{t-4}$ & $0.05(2.22)$ & $-0.09(-0.75)$ & $-0.03(-1.97)^{*}$ & $-0.06(-0.86)$ \\
\hline DGAS $_{t-5}$ & $0.01(0.55)$ & $-0.22(-1.69)$ & $0.05(-0.43)$ & $0.07(1.04)$ \\
\hline DGAS $_{t-6}$ & $0.10(3.00)^{*}$ & $1.19(7.71)^{*}$ & $0.02(0.85)$ & $-0.11(-1.78)$ \\
\hline DGAS $_{t-7}$ & $-0.06(-2.39)^{*}$ & $0.53(4.30)^{*}$ & $0.03(2.10)^{*}$ & $-0.01(-0.04)$ \\
\hline DGAS $_{t-8}$ & $-0.01(-0.85)$ & $-0.22(-2.57)^{*}$ & $-0.08(-4.15)^{*}$ & $-0.30(-3.16)^{*}$ \\
\hline D1 & 0.86 & 1.92 & 1.29 & 3.56 \\
\hline
\end{tabular}

$t$ Statistics are given in parentheses (). Probabilities are given in parentheses []. Significance at $5 \%$ is denoted with asterisks Log-likelihood: 114.023, AIC criterion: 6.17, LR linearity test: 11.24 [0.03], $\chi^{(2)}=[0.029], \chi^{(4)}=[0.034]$, Davies $=[0.014]$, Vector normality test: $\chi^{(4)}=3.14$ [0.33], Vector hetero test: $\chi^{(24)}=11.12$ [0.64], Vector portmanteau(5): $\chi^{(12)}=13.11[0.29]$

The regime probabilities show that, staying in the low inflation is 0.47 and staying in the high inflation regime is 0.64 . Therefore, there is a high probability of transition from low inflation to high inflation, and a sudden increase in oil prices has a crisis period effect on core inflation. Also first regime tends to last 2.11 months on average, while the second regime is more persistent, lasting 2.80 months. The results obtained for CINF-DGAS are reported in Table 10.

According to Table 10, the effect of gasoline price change on core inflation is significant and positive in time $t-4$. This finding reveals that gasoline price shocks have a delayed effect on core inflation. Transition probabilities and regime durations are shown in Table 11.

MSIAH(2)-VARX (8) is selected and the transition probabilities suggest that the persistence of the high inflation regime is higher than that of the low inflation regime. Regime 1 is determined to last, on average, 2.37 months, and the average duration of the high inflation phase is
Table 11 Transition probabilities, regime durations for MSIAH(2)$\operatorname{VARX}(8)$

\begin{tabular}{lllll}
\hline Transition probabilities & Regime 1 & Regime 2 & Nobs & Durations \\
\hline Regime 1 & 0.42 & 0.58 & 33.6 & 2.37 \\
Regime 2 & 0.30 & 0.70 & 45.4 & 3.27 \\
\hline
\end{tabular}

3.27 months. Also, it is found that the sudden increase in gasoline prices has a pass-through effect to core inflation.

Afterward, the filtered and smoothed probabilities are estimated and the graphics are given in Fig. 1.

The regime graphics show that the number of phases is high, there are rapid transitions, and the time remaining in one regime is short. In addition, graphics indicate that all models stay at high inflation longer than at low inflation. Impulse-response analyses were made after regime transition probabilities were reviewed, and the graphics are given in Fig. 2. 


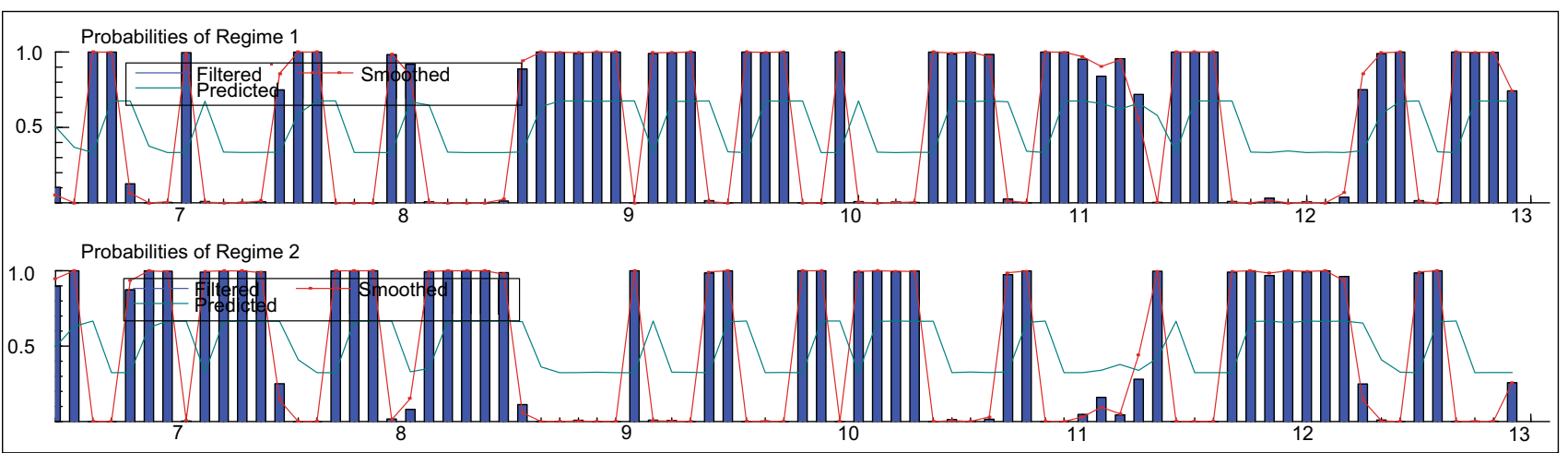

Filtered and smoothed probabilities for INF-OIL

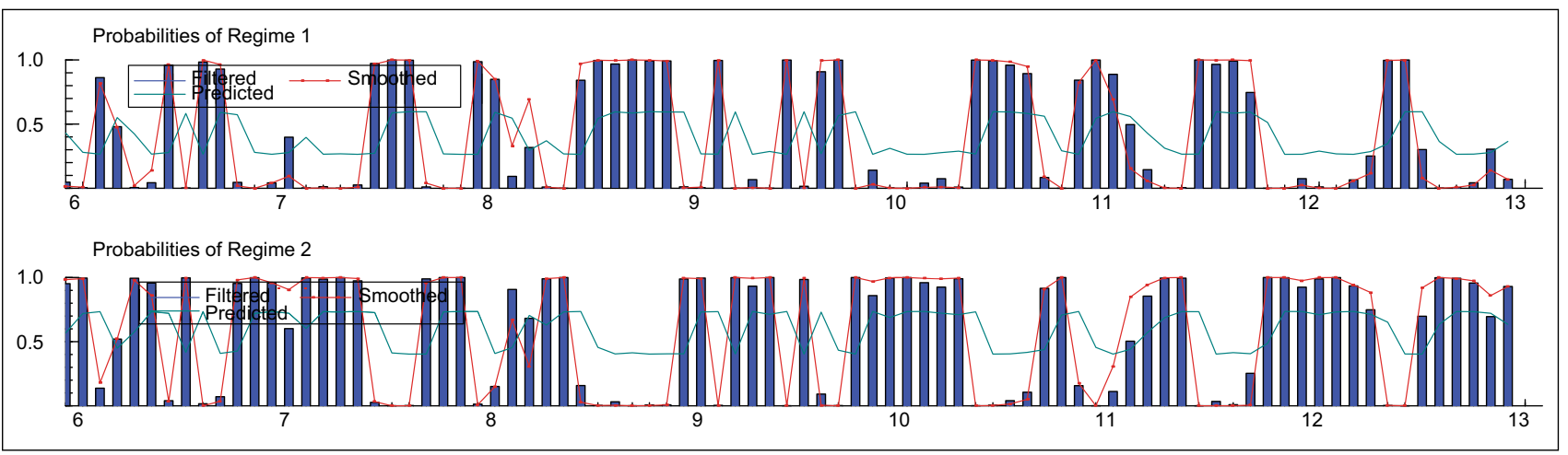

Filtered and smoothed probabilities for INF-DGAS

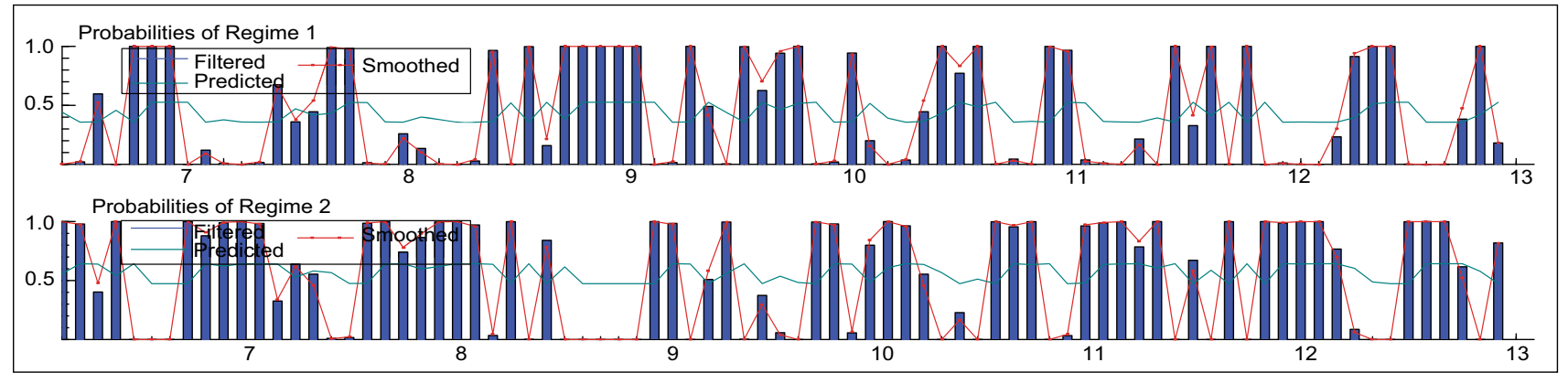

Filtered and smoothed probabilities for CINF-OIL

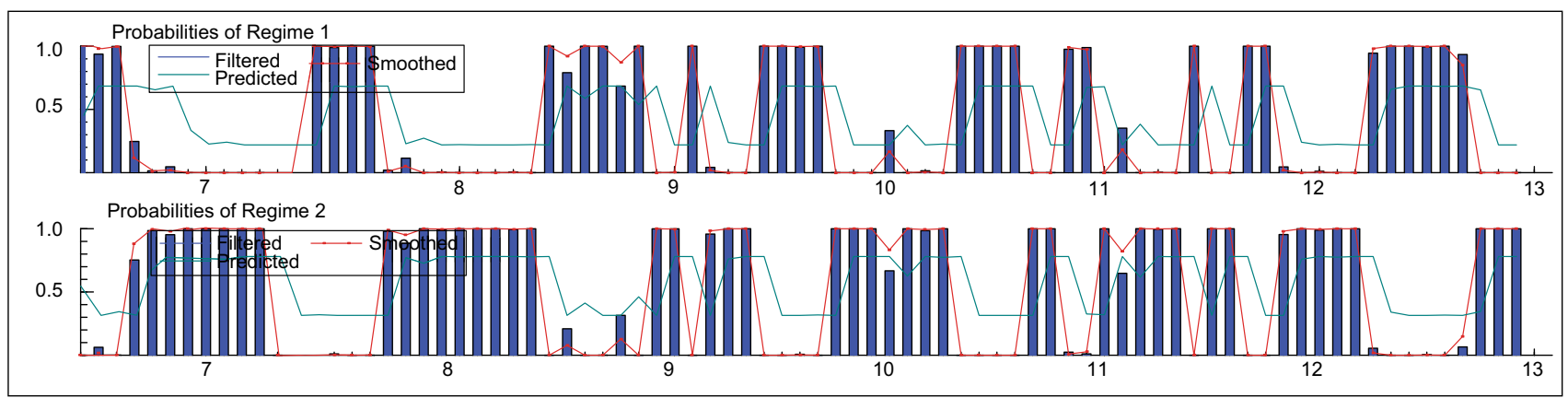

Filtered and smoothed probabilities for CINF-DGAS

Fig. 1 Regime probabilities graphics 

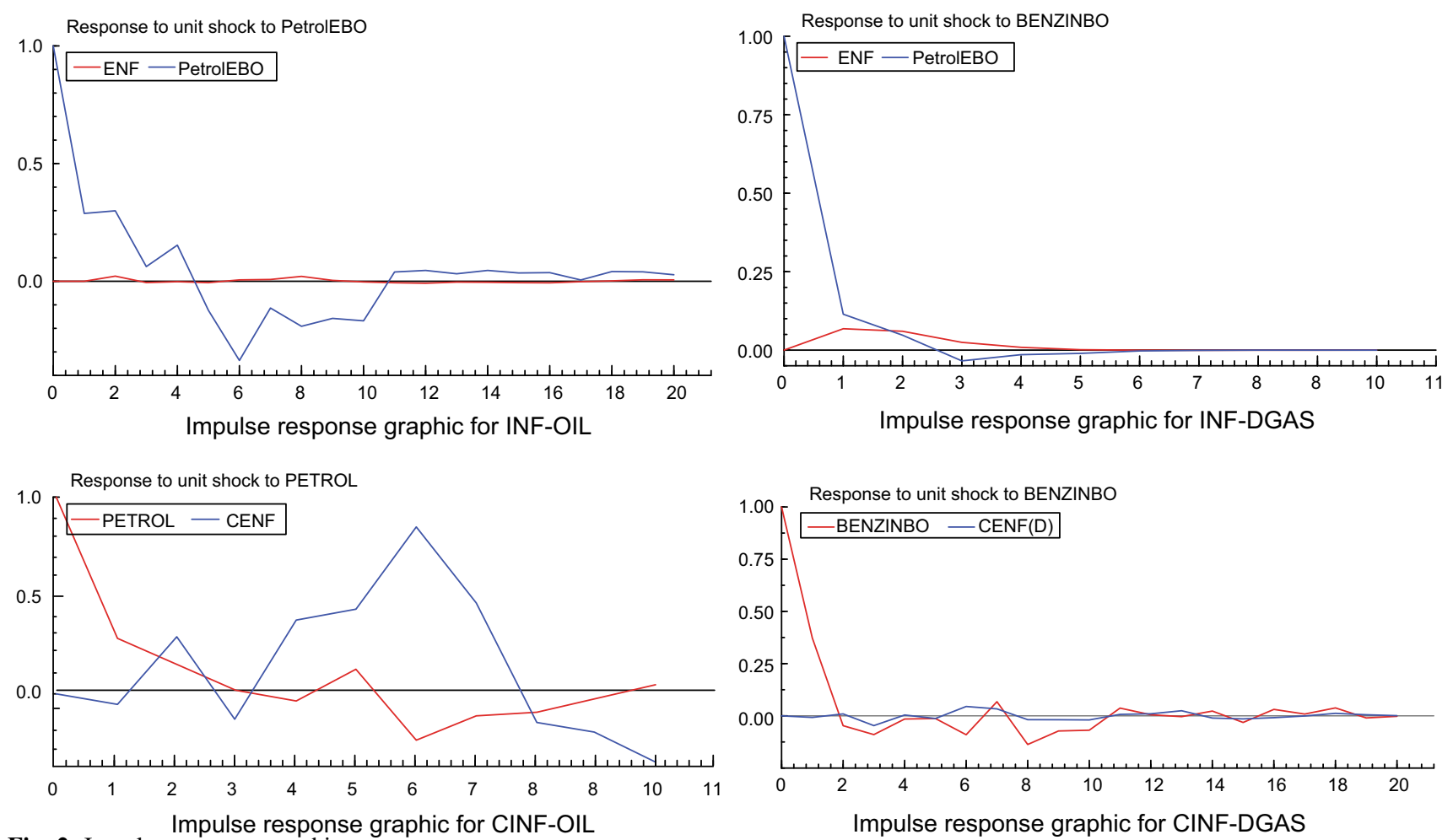

Fig. 2 Impulse-response graphics

When the impulse-response graphics in Fig. 2 are examined, it is seen that, in case of a shock in the price of oil, inflation shows a small and positive response in the second and eighth months, then turns back to its former equilibrium level and becomes stable after the eighth month. This shows that the inflation target level does not deviate because of the increase in crude oil prices. When there is a shock in gasoline prices, it is seen that inflation responds by increasing from the first to the fifth month, with the response disappearing from the sixth month onward. This reveals that increases in gasoline prices cause an inflationary response, and when there is deviation from monthly inflation targets, a significant part of this can be due to the increases in domestic gasoline prices. Core inflation shows response to a shock in crude oil prices with a small decrease in the first period, an increase in the second period, and a high increase between the fourth and seventh periods. After the eighth period, it can be said that the response ends. When there is a sudden increase in domestic gasoline prices, core inflation responds with an increase in the seventh and eleventh months and then loses the impact later on. These findings reveal that the response of core inflation would last for 1 year with shocks in domestic gasoline prices, and therefore there is a long-term passthrough effect.

In this context, the finding of the present study suggests that the effect of crude oil and domestic gasoline price changes on consumer prices and core inflation differs according to regimes, and this indicates that increases in crude oil prices have no inflationary effects, while increases in gasoline prices do. This result is consistent with the finding of Kibritcioglu and Kibritcioglu (1999), where the authors conclude that a $20 \%$ increase in crude oil price has an insignificant effect on general price levels, as well as the finding of Oksuzler and Ipek (2011), who find that there is no causality between oil prices and inflation. However, it is noteworthy to mention that in these studies neither the nonlinear relationship between the variables nor the effect of gasoline prices (which is the main source of inflation) was analyzed.

\section{Conclusion}

Inflation and the price of oil are seen by academicians and politicians as being connected. The reason for this opinion is that oil is a major factor in the economy. Especially in the non-oil-producing countries, oil price fluctuations can have a great impact on economic variables such as consumer prices and core inflation. Also, oil price and inflation series may exhibit nonlinear behavior due to factors such as policy changes and energy crises.

In this context, the effects of crude oil and domestic gasoline price changes on consumer price inflation and core inflation have been investigated with MS-VAR models in Turkey for the period October 2005-December 2012. 
Two regimes have been determined for all variables, and the existence of different regimes has revealed that the series show different behaviors in each regime. This result indicates that the political targets should be changed depending on the change of the inflation rate. Additionally, the findings of the study show that Turkish policy makers should not ignore the pass-through of oil and domestic gasoline prices to macroeconomic variables such as consumer price inflation and core inflation. Also, we find that, unlike the previous studies carried out for Turkey, the impact of sudden increases in gasoline prices on consumer inflation and core inflation is more significant than shocks in crude oil prices. The probabilities of being in low and high inflation regimes and transition from one to another are very close in the inflation/crude oil price relationship. In the inflation/domestic gasoline price relationship, the probability is higher for remaining in high inflation and for transition from low to high inflation. This indicates that increases in domestic gasoline prices affect the inflation rate and make a crisis impact.

Open Access This article is distributed under the terms of the Creative Commons Attribution License which permits any use, distribution, and reproduction in any medium, provided the original author(s) and the source are credited.

\section{References}

Aktas E, Ozenc C, Arica F. The impact of oil prices in Turkey on macroeconomics. Pune: Munich Personal RePEc Archive; 2010.

Álvarez LJ, Hurtado S, Sánchez I, et al. The impact of oil price changes on Spanish and euro area consumer price inflation. Econ Model. 2011;28(1):422-31.

Aydin L, Acar M. Economic impact of oil price shocks on the Turkish economy in the coming decades: a dynamic CGE analysis. Energy Policy. 2011;39(3):1722-31.

Berument H, Tasci H. Inflationary effect of crude oil prices in Turkey. Phys A. 2002;316(1):568-80.

Catik AN, Onder AO. Inflationary effects of oil prices in Turkey: a regime-switching approach. Emerg Mark Financ Trade. 2011;47(5):125-40.

CBRT Monetary Policy Report. http://www3.tcmb.gov.tr/yillikrapor/ 2012/en/m-2-1-2.php. 2012.

Celik T, Akgul B. Changes in fuel oil prices in Turkey: an estimation of the inflation effect using VAR analysis. J Econ Bus. 2011;2:11-21.

Cologni A, Manera M. The asymmetric effects of oil shocks on output growth: a Markov-switching analysis for the G-7 countries. Econ Model. 2009;26(1):1-29.

Cologni A, Manera M. Oil prices, inflation and interest rates in a structural co-integrated VAR model for the G-7 countries. Energy Econ. 2005;30(3):856-88.

Cunado J, Perez de Gracia F. Do oil price shocks matter? Evidence for some European countries. Energy Econ. 2003;25(2):137-54.

Cunado J, Pérez de Gracia F. Oil prices, economic activity and inflation: evidence for some Asian countries. Quart Rev Econ Financ. 2005;45(1):65-83.

Davis S J, Loungani P and Mahidhara R. Regional labor fluctuations: oil shocks, military spending, and other driving forces. Manuscript, Working Paper, 1996.
De Gregorio J, Landerretche O and Neilson C. Another pass-through bites the dust? Oil prices and Inflation. Central Bank of Chile Working Papers. 2007. No. 417.

Dempster AP, Laird NM, Rubin DB. Maximum likelihood from incomplete data via the EM algorithm. J R Stat Soc. 1977;39(1):1-38.

Dickey DA, Fuller WA. Distribution of the estimators for autoregressive time series with a unit root. J Am Stat Assoc. 1979;74(36):427-31.

Dotsey M, Reid M. Oil shocks, monetary policy, and economic activity. Econ Rev. 1992;78(4):14-27.

Du X, Yu CL, Hayes DJ. Speculation and volatility spillover in the crude oil and agricultural commodity markets: a Bayesian analysis. Energy Econ. 2011;33(3):497-503.

Ewing BT, Thompson MA. Dynamic cyclical co-movements of oil prices with industrial production, consumer prices, unemployment, and stock prices. Energy Policy. 2007;35(11):5535-40.

Farzanegan MR, Markwardt G. The effects of oil price shocks on the Iranian economy. Energy Econ. 2009;31(1):134-51.

Federal Reserve Economic Data http://research.stlouisfed.org/fred2/.

Goldfeld SM, Quandt RE. A Markov model for switching regressions. J Econom. 1973;1(1):3-15.

Goodwin TH. Business-cycle analysis with a Markov-switching model. J Bus Econ Stat. 1993;11(3):331-9.

Gray SF. Modeling the conditional distribution of interest rates as a regime-switching process. J Financ Econ. 1996;42(1):27-62.

Hall SG, Psaradakis Z, Sola M. Detecting periodically collapsing bubbles: a Markov-switching unit root test. J Appl Econom. 1999;14(2):143-54

Hamilton JD. A new approach to the economic analysis of nonstationary time series and the business cycle. Econometrica. 1989;57:357-84.

Hamilton JD. This is what happened to the oil price-macroeconomy relationship. J Monet Econ. 1996;38(2):215-20.

Hansen BE. The likelihood ratio test under nonstandard conditions: testing the Markov switching model of GNP. J Appl Econom. 1992; 7(1):61-82.

Hooker MA. Are oil shocks inflationary?: Asymmetric and nonlinear specifications versus changes in regime. J Money Credit Bank. 2002;34(2):540-61.

Huntington HG. Crude oil prices and US economic performance: where does the asymmetry reside? Energy J. 1998;19(4):107-32.

Kahn GA, Hampton JR. Possible monetary policy responses to the Iraqi oil shock. Econ Rev. 1990;2:19-32.

Kibritcioglu A, Kibritcioglu B. Inflationary effects of increases in prices of imported crude oil and oil products in Turkey. T. C. Başbakanlık Hazine Müsteşarlığı Araştırma ve İnceleme Dizisi. 1999;21:77-96.

Kilian L, Vigfusson RJ. Pitfalls in estimating asymmetric effects of energy price shocks. Cent Econ Policy Res. 2009;23(3):27-52.

Kilian L, Murphy DP. The role of inventories and speculative trading in the global market for crude oil. J Appl Econom. 2013; 29(3):454-78.

Koop G, Pesaran M, Potter S. Impulse response analysis in nonlinear multivariate models. J Econom. 1996;74(1):119-47.

Krolzig HM. Econometric modeling of Markov-switching vector autoregressions using MSVAR for Ox. 1998. Oxford: Institute of Economics and Statistics and Nuffield College; 1998.

Krolzig HM. Markov-switching vector autoregressions: modelling, statistical inference, and application to business cycle analysis. Berlin: Springer; 1997.

LeBlanc M, Chinn M D. Do high oil prices presage inflation? The evidence from G-5 countries. SCCIE Working Paper. 2004.

Medina J P, Soto C. The Chilean business cycles through the lens of a stochastic general equilibrium model. Central Bank of Chile Working Papers. 2007. No: 457. 
Mork KA. Oil and the macro economy. When prices go up and down: an extension of Hamilton's results. J Polit Econ. 1989;97(3): $740-4$.

Nazlioglu S, Soytas U. World oil prices and agricultural commodity prices: evidence from an emerging market. Energy Econ. 2011;33(3):488-96.

Oksuzler O, Ipek E. The effects of the world oil price changes on growth and inflation: example of Turkey. Zonguldak Karaelmas University. J Soc Sci. 2011;7(14):16-21.

Olomola PA, Adejumo AV. Oil price shock and macroeconomic activities in Nigeria. Int Res J Financ Econ. 2006;3(1):28-34.

OPET Pump Prices. http://www.opet.com.tr/tr/PompaFiyatlariArsiv. aspx ?cat $=4 \& \mathrm{id}=34$.

Peker O, Mercan M. The inflationary effect of price increases in oil products in Turkey. Ege Acad Rev. 2011;11(4):553-62.

Reboredo JC. How do crude oil prices co-move? A copula approach. Energy Econ. 2011;33(5):948-55.
Robert H, Tatom JA. Energy resources and potential GNP. Fed Reserve Bank St. Louis Rev. 1977;59:10-24.

Santini D. The energy-squeeze model: energy price dynamics in U.S. business cycles. Int J Energy Syst. 1986;5(1):159-94.

Tang W, Wu L, Zhang Z. Oil price shocks and their short- and long-term effects on the Chinese economy. Energy Econ. 2010;32:3-14.

Tsay RS. Testing and modeling multivariate threshold models. J Am Stat Assoc. 1998;93(443):1188-202.

Turkish Statistical Institute, Main Statistics. http://www.tuik.gov.tr/ UstMenu.do?metod=temelist.

Van Den Noord P, André C. Why has core inflation remained so muted in the face of the oil shock?. Mexico: OECD Publishing; 2007.

Yaylali M, Lebe F. Effects of important crude oil prices on macroeconomic activities in Turkey. Marmara Üniv IIBF Derg. 2012;32(1):43-68. 